\title{
In vitro evaluation of folic acid-conjugated redox-responsive mesoporous silica nanoparticles for the delivery of cisplatin
}

This article was published in the following Dove Press journal:

International Journal of Nanomedicine

23 November 2016

Number of times this article has been viewed

\author{
Merlis P Alvarez-Berríos' \\ Juan L Vivero-Escoto ${ }^{2,3}$ \\ 'Department of Science and \\ Technology, Inter American University \\ of Puerto Rico, Ponce, Puerto Rico, \\ ${ }^{2}$ Department of Chemistry, ${ }^{3}$ Center \\ for Biomedical Engineering and \\ Science, University of North Carolina \\ at Charlotte, Charlotte, NC, USA
}

Correspondence: Juan L Vivero-Escoto Department of Chemistry, University of North Carolina at Charlotte, 920I University City Boulevard, Charlotte, NC 28223, USA

$\mathrm{Tel}+\mathrm{I} 7046875239$

Fax +I 7046870960

Email jviveroe@uncc.edu

\begin{abstract}
The use of cisplatin(IV) prodrugs for the delivery of cisplatin have gained significant attention, because of their low toxicity and reactivity. Recent studies have shown that targeted cisplatin(IV)-prodrug nanoparticle-based delivery systems can improve the internalization of the cisplatin(IV) prodrug. We hypothesized that folic acid-conjugated mesoporous silica nanoparticles (MSNs) containing cisplatin(IV) prodrug could target cancer cells that overexpress the folate receptor and deliver the active cisplatin drug upon intracellular reduction. To prove this hypothesis, internalization and localization studies in HeLa cancer cells were performed using flow cytometry and confocal microscopy. The ability of MSNs to escape from the endolysosomal compartments, the formation of DNA adducts, and the cytotoxic effects of the MSNs were also evaluated. Our results confirmed that this MSN-based delivery platform was capable of delivering cisplatin into the cytosol of HeLa cells, inducing DNA adducts and subsequent cell death.
\end{abstract}

Keywords: cancer treatment, cisplatin prodrug, intracellular delivery, folic acid, mesoporous silica

\section{Introduction}

For years, chemotherapy has been regarded as the standard systemic therapy for a variety of malignancies. ${ }^{1,2}$ The platinum-based anticancer drug cisplatin is clinically used to treat a wide variety of cancers, including testicular, ovarian, bladder, and nonsmall-cell lung cancer. ${ }^{3,4}$ The mechanism by which this classical platinum drug elicits an anticancer effect is through the formation of DNA adducts that interfere with the DNA-replication process, leading to cell death. ${ }^{3,4}$ Despite the extensive application of cisplatin in oncology, there are various side effects that restrict its use. ${ }^{5-7}$ When cisplatin is transported through the bloodstream, a percentage of the drug is lost, due to its interaction with proteins and other side reactions, which induces undesirable side effects, such as anemia, vomiting, nausea, and kidney damage. ${ }^{8,9}$ Additionally, some types of cancer can develop resistance after several treatments, affecting the final outcome of this anticancer agent. ${ }^{10}$ Platinum(IV) prodrugs, which release cisplatin upon reduction, have been explored as promising alternatives to overcome these challenges., ${ }^{4,9,11,12}$ The physicochemical and biological properties of platinum(IV) prodrugs differ significantly from those of their platinum(II) counterparts. For example, the saturated, kinetically more inert coordination sphere of platinum(IV) is more resistant to ligand-substitution reactions, thus minimizing unwanted side reactions with biomolecules prior to DNA binding. In addition, the two extra ligands provide a means to impart and fine-tune 
desired biological properties, such as lipophilicity, redox stability, cancer-cell targeting, and improved cellular uptake. Moreover, the additional ligands also facilitate the attachment to nanoparticles and other carrier systems. ${ }^{4}$ Although platinum(IV) complexes can platinate DNA in their oxidized form, the formation of cytotoxic lesions by ligand substitution occurs in a matter of weeks. The reduction of the platinum(IV) center to platinum(II), through the loss of two ligands, is thought to be essential for the anticancer activity of these agents. ${ }^{4}$

One of the important advantages of platinum(IV) prodrugs is their ability to be easily incorporated into drug-delivery devices, in particular those with nanoscale dimensions. ${ }^{4,8}$ Several platforms have been used to incorporate cisplatin or other platinum-based drugs, such as carbon-based materials, coordination polymers, metal-organic frameworks, polymeric micelles, and proteins..$^{413-17}$ Some of these platinum drug-delivery systems are already being administered, while others are being tested in clinical trials. ${ }^{4}$

Inorganic nanoparticles, such as gold, polysilsesquioxane, upconversion, mesoporous silica, and silica nanoparticles have been used for the transport and delivery of platinum(IV) prodrugs. ${ }^{4,18-22}$ Mesoporous silica nanoparticles (MSNs) have gained significant interest, because of their biocompatibility, ability to carry large payloads, and ease of functionalization with targeting molecules. ${ }^{23-27}$ A wide variety of approaches have been developed using MSNs as nanocarriers for delivering different types of platinum(IV) prodrugs, but the cisplatin(IV) prodrug has been the most popular anticancer drug. ${ }^{20} \mathrm{Gu}$ et al reported on MSN-based systems for the efficient delivery of cisplatin. ${ }^{28-30}$ The authors selectively grafted a high density of carboxylic acid groups, which were used to complex to cisplatin, onto the surfaces of the MSNs. This approach increased drug-loading efficiency and greatly enhanced growth-inhibition effects against the MCF7, HeLa, and A549 cancer cell lines. In a different study, a fluorescent MSN-based cisplatin(IV) prodrug-delivery system was developed and tested in vitro. ${ }^{31}$ This platform took advantage of the reductive environment of cancer cells to release the active cisplatin. This delivery system not only demonstrated enhanced cellular uptake but also showed significant drug effect. The use of combination therapy using MSNs as carriers to deliver cisplatin with other therapeutic agents has recently been explored. ${ }^{32-35}$ Munaweera et al demonstrated that the co-delivery of nitric oxide and cisplatin improved the treatment of non-small cell lung cancer cells. ${ }^{33}$ All these results indicated that the cellular uptake and efficacy of cisplatin were improved using an MSN platform. However, few of these papers looked at the benefits of modifying the
MSN material with targeting agents. Targeting groups that enable nanocarriers to target cancer cells efficiently are constantly sought. ${ }^{36-38}$ This approach involves the functionalization of nanovehicles with targeting moieties that bind to receptors that are overexpressed on the surface of cancer cells, thereby triggering receptor-mediated endocytosis. ${ }^{36-39}$ These systems could enhance the accumulation of chemotherapeutics in cancer cells and lead to higher efficacy and reduced side effects. ${ }^{37}$

In this work, we functionalized MSNs with folic acid (FA) to target cancer cells that overexpress folate receptors. The folate receptor is a cell-surface receptor that is considered a promising target for detection and treatment of cancer. ${ }^{40-42}$ It is overexpressed in many types of cancer, such as ovarian, cervical, breast, lung, kidney, colorectal, and brain. ${ }^{41}$ It is known that FA has a high affinity for this receptor, even when it is conjugated to drug-delivery systems. ${ }^{41} \mathrm{MSN}$ s have been previously functionalized with FA for the target-specific delivery of anticancer agents. ${ }^{32,43-46}$ These delivery systems have enhanced the toxic effects of different drugs, such as doxorubicin, cisplatin, and pemetrexed, against cancer cells that overexpress FA receptors. However, a thorough investigation on the trafficking and delivery efficiency of cisplatin(IV) prodrug from FA-conjugated MSNs has not been reported. In this study, a cisplatin(IV) prodrug was chemically attached to the inside of the pores of MSNs, which were further decorated with an FA targeting group (Figure 1). We hypothesized that this MSN-based nanocarrier would be able to target cancer cells that overexpress folate receptors, and that the delivery of cisplatin would be triggered by the intracellular reductive environment. The released cisplatin would have the ability to induce DNA adducts, leading to cell death. ${ }^{4}$ To test this hypothesis, internalization and localization studies in HeLa cancer cells were performed using flow cytometry and confocal microscopy. In addition, the ability of MSNs to escape from endolysosomal compartments was evaluated. Finally, DNA-adduct formation and cytotoxicity studies were performed. Our results indicated that the FA-conjugated MSNs developed in this work can specifically target HeLa cells, which overexpressed FA receptors. In addition, this delivery platform was capable of efficiently delivering cisplatin molecules into the cytosol of HeLa cells, which are further transported to the nucleus, inducing DNA adducts and subsequent cell death.

\section{Materials and methods}

Chemicals

Cetyltrimethylammonium bromide (CTAB), mesitylene, 3-aminopropyl (AP) triethoxysilane (APTES), tetraethyl 


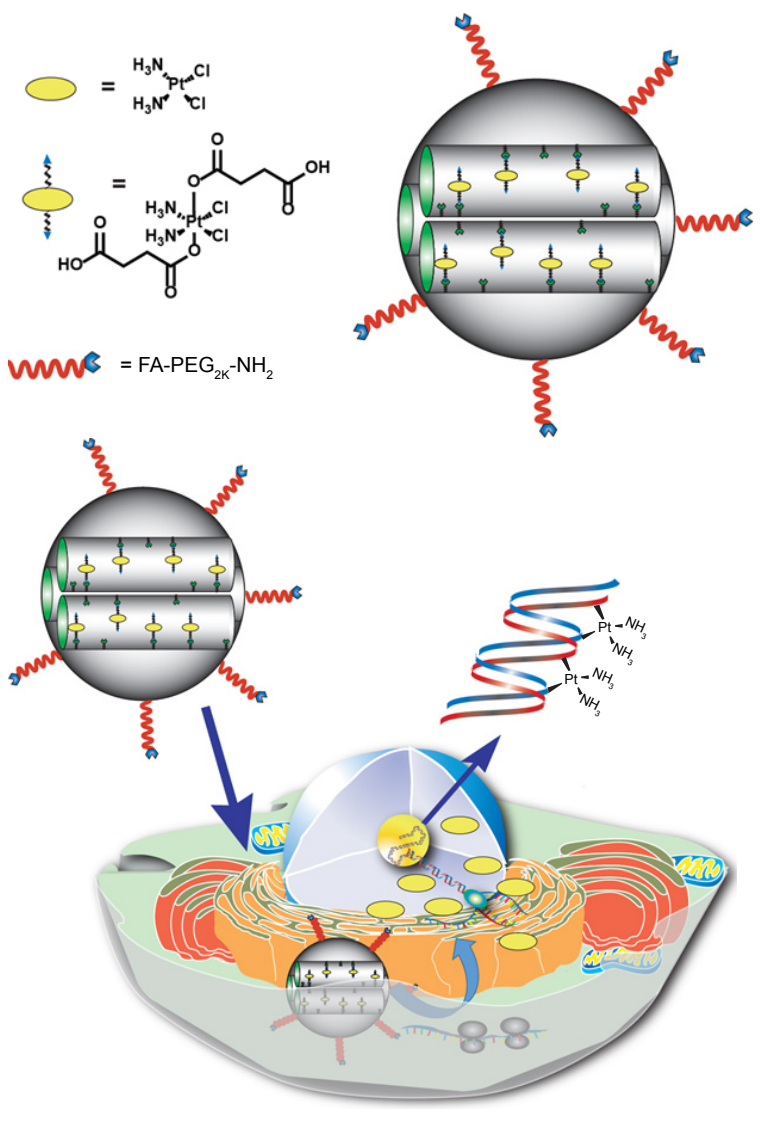

Figure I Schematic representation of the FA-conjugated cisplatin(IV) prodrug MSN platform developed in this work.

Notes: The MSN-delivery system contains cisplatin(IV) prodrug chemically attached to the surface of the nanoparticle and is decorated with FA-PEG-NH that targets FA receptors overexpressed in HeLa cancer cells. The FA-conjugatedcisplatin(IV) prodrug MSNs are internalized through a receptor-mediated endocytosis mechanism, escape from lysosomes, and release the cisplatin, due to the highly reducing environment found in the cytosol of cancer cells. The released cisplatin travels to the cell nucleus to form DNA adducts, which triggers apoptosis. Abbreviations: FA, folic acid; MSN, mesoporous silica nanoparticle; PEG, polyethylene glycol.

orthosilicate, cisplatin, hydrogen peroxide solution $(11.3 \%$ $\mathrm{v} / \mathrm{v}$ ), succinic anhydride, trimethylamine, 3-(triethoxysilyl) propyl isocyanate, ascorbic acid, and FA were purchased from Sigma-Aldrich (St Louis, MO, USA). Polyethylene glycol (PEG; 2K) was purchased from Alfa Aesar (Haverhill, MA, USA). 1-Ethyl-3-(3-dimethylaminopropyl)carbodiimide was purchased from Oakwood Products Inc (West Columbia, SC, USA). All the reagents and solvents were used without further purification.

\section{Methods}

The hydrodynamic diameter and $\zeta$-potential of the nanoparticles in water were obtained using a particle-size analyzer (Zetasizer Nano; Malvern Instruments, Malvern, UK). The organic content was determined by gravimetric analysis (TGA/SDTA851; Mettler Toledo, Columbus, OH, USA). For this experiment, samples were heated from $25^{\circ} \mathrm{C}$ to $600^{\circ} \mathrm{C}$ under nitrogen at a rate of $5^{\circ} \mathrm{C} / \mathrm{min}$. Particle size and morphology were determined using field-emission scanning electron microscopy (SEM; Raith150, Raith, Dortmund, Germany). The surface area was estimated by the Brunauer-Emmett-Teller (BET) method using a Nova 2200e surface-area and pore-size analyzer (Quantachrome Instruments, Boynton Beach, FL, USA). The amount of cisplatin was quantified using atomic absorption spectrometry (Analyst 200) equipped with a graphite furnace HGA 900 (PerkinElmer, Waltham, MA, USA).

\section{Synthesis of AP-MSNs}

AP-MSNs were synthesized using a surfactant-template approach previously reported in the literature, with slight modifications. ${ }^{47}$ Briefly, $100 \mathrm{mg}$ of CTAB $(0.274 \mathrm{mmol})$ were dissolved in $50 \mathrm{~mL}$ of nanopure water, followed by the addition of $0.7 \mathrm{~mL}$ of mesitylene $(5.032 \mathrm{mmol})$ and $0.35 \mathrm{~mL}$ of an $\mathrm{NaOH}$ aqueous solution (2 M). This solution was stirred for 1 hour at $80^{\circ} \mathrm{C}$. After this period of time, $69.8 \mu \mathrm{L}$ of 3-APTES $(0.298 \mathrm{mmol})$ and $0.5 \mathrm{~mL}$ of tetraethyl orthosilicate $(2.256 \mathrm{mmol})$ were added to the $\mathrm{CTAB}$ solution. The mixture was allowed to react for an additional period of 2 hours at $80^{\circ} \mathrm{C}$. At the end of the reaction, the MSNs were washed three times with ethanol and the CTAB surfactant removed from the pores by refluxing the nanoparticles in a solution of methanol containing $0.86 \mathrm{M}$ of hydrochloric acid at $60^{\circ} \mathrm{C}$ overnight. Afterward, the MSNs were washed three times with ethanol and resuspended in the same solvent.

\section{Synthesis and characterization of the cisplatin(IV) prodrug}

The cisplatin(IV) prodrug (cis, cis,trans- $\left[\mathrm{Pt}\left(\mathrm{NH}_{3}\right)_{2} \mathrm{Cl}_{2}\left(\mathrm{O}_{2}\right.\right.$ $\left.\left.\mathrm{CCH}_{2} \mathrm{CH}_{2} \mathrm{CH}_{2} \mathrm{CO}_{2} \mathrm{H}\right)_{2}\right]$ ) was synthesized using a modified procedure. ${ }^{9,11,31}$ The first step was the oxidation of cisplatin using hydrogen peroxide. First, $100 \mathrm{mg}$ of cisplatin $(0.333 \mathrm{mmol})$ were dissolved in a solution of hydrogen peroxide in water $(11.3 \% \mathrm{v} / \mathrm{v})$. Then, this solution was allowed to react at $70^{\circ} \mathrm{C}$ for 5 hours under nitrogen atmosphere. Afterward, the product was washed with cold $\mathrm{H}_{2} \mathrm{O}$, ethanol, and diethyl ether and allowed to dry overnight. Yield: $34.7 \mathrm{wt} \%$. Fourier-transform infrared (IR; $\left.\mathrm{cm}^{-1}\right): 3,513$ (O-H), 3,253 (N-H). Dihydroxycisplatin(IV) (0.372 mmol, $123.6 \mathrm{mg}$ ) was reacted with succinic anhydride $(1.489 \mathrm{mmol}$, $148.9 \mathrm{mg}$ ) in $4 \mathrm{~mL}$ of dimethyl sulfoxide (DMSO) at $70^{\circ} \mathrm{C}$ overnight. After the reaction time, the product was dried under vacuum and recrystallized in cold acetone. Yield: $62.9 \mathrm{wt} \%$. ${ }^{1} \mathrm{H}$-nuclear magnetic resonance $(300 \mathrm{MHz}$, DMSO-d $\left.\mathrm{d}_{6}, \mathrm{ppm}\right): 6.45\left(3 \mathrm{H}, \mathrm{s}, \mathrm{NH}_{3}\right) ; 2.34-2.32(4 \mathrm{H}, \mathrm{m}$, $\left.\mathrm{CH}_{2} \mathrm{CH}_{2} \mathrm{COOH}\right) ;{ }^{13} \mathrm{C}$-nuclear magnetic resonance $(300 \mathrm{MHz}$, 
DMSO-d $\left._{6}, \mathrm{ppm}\right): 184.6$ (C[O]OPt), $179.1(\mathrm{COOH}), 35.7$ $\left(\mathrm{PtOC}=\mathrm{OCH}_{2}\right), 34.7\left(\mathrm{CH}_{2} \mathrm{COOH}\right)$. Fourier-transform IR $\left(\mathrm{cm}^{-1}\right): 3,453(\mathrm{O}-\mathrm{H}), 3,263(\mathrm{~N}-\mathrm{H})$.

\section{Synthesis of cisplatin(IV)-MSNs}

To synthesize cisplatin(IV)-loaded MSNs, $100 \mathrm{mg}$ of AP-MSNs were resuspended in $10 \mathrm{~mL}$ of DMSO, followed by the addition of $27.3 \mu \mathrm{L}(0.196 \mathrm{mmol})$ of triethylamine. Then, $5 \mathrm{~mL}$ of DMSO solution containing $25 \mathrm{mg}$ of cisplatin prodrug $(0.047 \mathrm{mmol})$ and $9 \mathrm{mg}$ of 1-ethyl-3(3-dimethylaminopropyl)carbodiimide- $\mathrm{HCl}(0.047 \mathrm{mmol})$ was added to the AP-MSN suspension. This reaction mixture was stirred for 48 hours at room temperature, after which the cisplatin(IV)-loaded MSNs were washed three times with ethanol and stored in the same solvent. The supernatants obtained from the reaction and each washing solution were used to determine the amount of cisplatin(IV) prodrug loaded into the nanoparticles. The solvent was removed and the solid residue dissolved in $10 \mathrm{~mL}$ of $\mathrm{HNO}_{3}$ $(0.1 \mathrm{M})$. The Pt content was determined by atomic absorption spectroscopy.

\section{Preparation of FA-cisplatin(IV)-MSNs}

To graft the targeting molecule onto the surface of cisplatin(IV)-MSNs, an FA-PEG-silane derivative was obtained following a multistep reaction. First, FA-PEG-NH was synthesized following a protocol previously reported in the literature, with slight modifications (see Supplementary materials for details of this synthesis, Figure S1). ${ }^{48,49}$ The FA-PEG-silane derivative was prepared in situ according to the following procedure: $25 \mathrm{mg}$ of FA-PEG-NH $(0.0102 \mathrm{mmol})$ were dissolved in $0.5 \mathrm{~mL}$ of DMSO, followed by the addition of $3.45 \mu \mathrm{L}$ of triethylamine $(0.0247 \mathrm{mmol})$ and $9.21 \mu \mathrm{L}(0.0372 \mathrm{mmol})$ of 3-(triethoxysilyl)propyl isocyanate. This mixture was stirred for 4 hours at room temperature. After this period of time, this solution was added to a suspension of cisplatin(IV)-MSNs (50 mg of material redispersed in $15 \mathrm{~mL}$ of ethanol), and the reaction mixture was refluxed at $90^{\circ} \mathrm{C}$ for 24 hours. The resulting material (FA-cisplatin[IV]-MSNs) was washed three times with ethanol. As a control, nontargeted cisplatin(IV)-MSNs covered with methoxy-PEG (MeO-PEG) were prepared by mixing $81.5 \mathrm{mg}$ of MeO-PEG silane with $50 \mathrm{mg}$ of cisplatin(IV)-MSNs in $15 \mathrm{~mL}$ of ethanol. This solution was refluxed at $90^{\circ} \mathrm{C}$ overnight and the final material (MeOcisplatin[IV]-MSNs) was washed three times with ethanol. The synthesis and characterization of the MeO-PEG-silane derivative is summarized in the Supplementary materials.

\section{Reduction of cisplatin(IV) prodrug to cisplatin}

Electrospray ionization (ESI) mass-spectrometry studies were performed to confirm the release of cisplatin through the reduction of the cisplatin(IV)-MSNs in solution. Cisplatin has the ability to covalently bind to guanosine and form the cis-Pt $\left[\left(\mathrm{NH}_{3}\right)_{2} \mathrm{Cl} \text { (guanosine) }\right]^{+}$complex. ${ }^{50}$ The presence of this cationic compound $(\mathrm{m} / \mathrm{z}=547.1)$ in the ESI mass spectrum is used as a marker to confirm the delivery of cisplatin from cisplatin(IV) nanocarriers under reductive conditions. ${ }^{50}$ Ascorbic acid is a reducing agent found in the intracellular environment of cancer cells, and it is known to reduce cisplatin(IV) complexes to cisplatin. For this experiment, $2 \mathrm{~mL}$ of an aqueous solution containing $17 \mathrm{mM}$ of ascorbic acid, $0.62 \mathrm{mM}$ of guanosine, and $2 \mathrm{mg} / \mathrm{mL}$ of FAcisplatin(IV)-MsNs was stirred at $37^{\circ} \mathrm{C}$ for 24 hours. The solution was filtered and the sample analyzed using an MSQ Plus ESI mass spectrometer (Thermo Fisher Scientific, Waltham, MA, USA). A control sample treated at the same conditions in the absence of ascorbic acid was also analyzed.

\section{Cell culture}

HeLa cells were obtained from the American Type Culture Collection, and were cultured in Roswell Park Memorial Institute (RPMI) medium supplemented with $10 \%$ fetal bovine serum, $1 \%$ penicillin, and $1 \%$ streptomycin. Cells were maintained at $37^{\circ} \mathrm{C}$ and $5 \% \mathrm{CO}_{2}$. Passages were performed when cells reached $70 \%-75 \%$ confluence. For all in vitro experiments, cells were cultured in free FA RPMI medium 24 hours before the experiment to avoid supersaturation of the folate receptor by the free FA present in the regular cell medium.

\section{Internalization and localization of FA-cisplatin(IV)-MSNs}

For internalization and localization studies, AP-MSNs were labeled with fluorescein isothiocyanate (FITC), as previously reported. ${ }^{47}$ Briefly, an FITC-silane molecule was prepared by stirring FITC ( $5 \mathrm{mg}, 0.0128 \mathrm{mmol}$ ) with $3 \mu \mathrm{L}$ of APTES $(0.0128 \mathrm{mmol})$ in $200 \mu \mathrm{L}$ of acetonitrile for 30 minutes at room temperature. The resulting FITC-silane derivative was added into a stirring CTAB (100 mg, $0.274 \mathrm{mmol})$ solution in water $(50 \mathrm{~mL})$ containing $69.8 \mu \mathrm{L}$ of APTES $(0.298 \mathrm{mmol})$ and $0.5 \mathrm{~mL}$ of tetraethyl orthosilicate $(2.256 \mathrm{mmol})$. This reaction mixture was allowed to react for 2 hours at $80^{\circ} \mathrm{C}$. The CTAB surfactant was removed from the pores of the nanoparticles as previously described. FITC-labeled MSNs (FITC-MSNs) were functionalized with FA-PEG-silane 
(FA-FITC-MSNs) or MeO-PEG-silane (MeO-FITC-MSNs) following the procedure described previously. To measure the internalization in HeLa cells, $2 \times 10^{5}$ cells were seeded in six-well plates and allowed to adhere overnight. These cells were incubated with $100 \mu \mathrm{g} / \mathrm{mL}$ of FA-FITC-MSNs or MeOFITC-MSNs for 6 hours. After this incubation period, cells were washed twice with warm RPMI medium, trypsinized, resuspended in a phosphate-buffered saline (PBS) solution containing $0.11 \%$ trypan blue, and analyzed using flow cytometry (BD LSRFortessa). The $0.11 \%$ trypan blue solution quenched the fluorescence of nanoparticles adsorbed on the cellular membrane, allowing only the quantification of internalized nanoparticles. Results are shown as normalized mean fluorescence intensity (MFI). $\left(\mathrm{MFI}_{\text {treated }}-\mathrm{MFI}_{\text {control }}\right) /$ $\mathrm{MFI}_{\text {control }} \cdot \mathrm{MFI}_{\text {treated }}$ represents the MFI of samples treated with $100 \mu \mathrm{g} / \mathrm{mL}$ of nanoparticles (FA-FITC-MSNs or MeOFITC-MSNs), and MFI control represents the MFI of untreated cells. Localization studies were carried out using confocal microscopy. A total of 20,000 cells were seeded in eightwell chamber slides and incubated overnight. Cells were exposed to $100 \mu \mathrm{g} / \mathrm{mL}$ of nanoparticles for 6 hour, washed twice with RPMI medium, and stained using a NucBlue ${ }^{\circledR}$ Live cell-staining 4',6-diamidino-2-phenylindole solution for 20 minutes at room temperature. Samples were washed twice with PBS and images taken using a confocal microscopy (Olympus FluoView FV1000) with a $60 \times$ waterimmersion objective.

\section{Endolysosomal escape of MSNs}

A total of 20,000 cells were seeded in eight-chamber slides and allowed to adhere overnight. After exposure to $100 \mu \mathrm{g} / \mathrm{mL}$ of FA-FITC-MSNs for 30 minutes, 1 hour, or 3 hours; cells were washed twice with warm RPMI medium and the endolysosomal compartments stained using RPMI medium containing $500 \mathrm{nM}$ of LysoTracker Red for 30 minutes at $37^{\circ} \mathrm{C}$. Afterward, cells were washed twice with PBS and images obtained using the Olympus Fluoview confocal microscope. Nanoparticles that were not able to escape from the endolysosome compartments are shown as yellow, because of the overlapping of red and green images.

\section{Detection of cisplatin adducts}

The ability of FA-cisplatin(IV)-MSNs to form DNA adducts was evaluated using a modified antibody, which has a specific affinity for the adduct formed between cisplatin and DNA. ${ }^{8,51-53}$ For controls, the cisplatin(IV) prodrug, MeO-cisplatin(IV)-MSNs, and cisplatin were also studied. To compare the formation of cisplatin adducts between the experimental group and controls at the same conditions, the experiment was performed at a specific concentration of platinum $(6.5 \mu \mathrm{M})$. A total of $2 \times 10^{5}$ cells were seeded in a six-well plate and allowed to adhere for 24 hours. After this period, cells were incubated with a solution of RPMI (FA free) medium containing $6.5 \mu \mathrm{M}$ of platinum for 24 hours. Then, the solution was removed and the cells washed twice with PBS, trypsinized, and fixed in $70 \%$ ethanol at $4^{\circ} \mathrm{C}$ for 2 hours. Samples were washed with PBS and incubated with a 1:125 dilution of the anticisplatin-modified DNA antibody (Abcam, Cambridge, UK) in PBS containing $100 \mathrm{mg} / \mathrm{mL}$ of digitonin at $4^{\circ} \mathrm{C}$ overnight. Cells were washed twice with PBS, resuspended in a 1:200 dilution of a goat antirat $\operatorname{IgG}(\mathrm{H}+\mathrm{L})$ secondary antibody (Abcam), and incubated for 2 hours at $4^{\circ} \mathrm{C}$. Afterward, cells were washed twice with PBS, resuspended in PBS, and analyzed using flow cytometry. The MFI is proportional to the number of adducts formed in the DNA.

\section{Cell cytotoxicity}

To allow a valid comparison between groups, concentrations of platinum were used, rather than molar concentrations of the compounds or complexes. A total of $5 \times 10^{3}$ cells were seeded per well onto a 96-well plate and incubated for 24 hours. After this period of time, cells were exposed to varying concentrations of platinum $(0.5-65 \mu \mathrm{M})$ for 48 hours. Then, cells were washed twice with PBS buffer and incubated for an additional 24 hours. After this incubation period, cytotoxicity measurements were performed in a spectrophotometer at $450 \mathrm{~nm}$ using a CellTiter $96^{\circledR}$ aqueous assay.

\section{Statistical analysis}

Unless otherwise specified, the sample size was $n=3$. Statistical analyses were conducted using Student's $t$-test (two-tailed distribution, two samples with unequal variances). Differences were considered significant at $P<0.05$.

\section{Results and discussion Preparation and characterization of FA-cisplatin(IV)-MSNs}

FA-cisplatin(IV)-MSNs were prepared by a multistep procedure that involved the synthesis and functionalization of MSNs with cisplatin(IV) prodrug and with FA-PEG as targeting agent (Figure 1). To synthesize the AP-MSNs, a co-condesation reaction in the presence of APTES mediated by $\mathrm{CTAB}$ as the surfactant template was followed. ${ }^{47}$ The structural properties of the MSN materials were determined by dynamic light scattering, $\zeta$-potential, SEM, and 
$\mathrm{N}_{2}$ sorption isotherms. MSNs were fabricated with diameters of $146.6 \pm 26.9 \mathrm{~nm}$, according to SEM images (Figure 2). The hydrodynamic diameter of these nanoparticles, as determined by dynamic light scattering, was $\sim 272 \mathrm{~nm}$ (Table 1 and Figure 2). The $\zeta$-potential was $34.4 \mathrm{mV}$, indicating the presence of the amine groups from APTES, which are protonated. The surface area of the MSNs was $766.1 \mathrm{~m}^{2} / \mathrm{g}$, based on the BET analysis of the $\mathrm{N}_{2}$ sorption isotherm (Figure 2). Next, the cisplatin(IV) prodrug was covalently conjugated to the amine groups on the interior surface of AP-MSNs through coupling chemistry mediated by EDC as the coupling agent. An increase in the organic content of $3.2 \mathrm{wt} \%$ in cisplatin(IV)-MSNs was observed in comparison to AP-MSNs, due to the presence of cisplatin(IV) prodrug. Additionally, BET analysis showed a decrease in surface area from 766.1 to $523.4 \mathrm{~m}^{2} / \mathrm{g}$, indicating that cisplatin prodrug molecules were able to fill the channels of the AP-MSNs (Table 1 and Figure 2). Moreover, the $\zeta$-potential decreased from 34.4 to $-1 \mathrm{mV}$, due to the presence of negatively

A

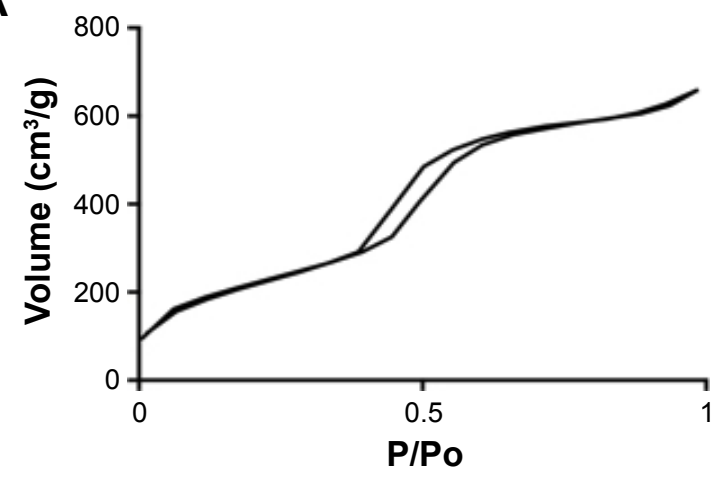

C

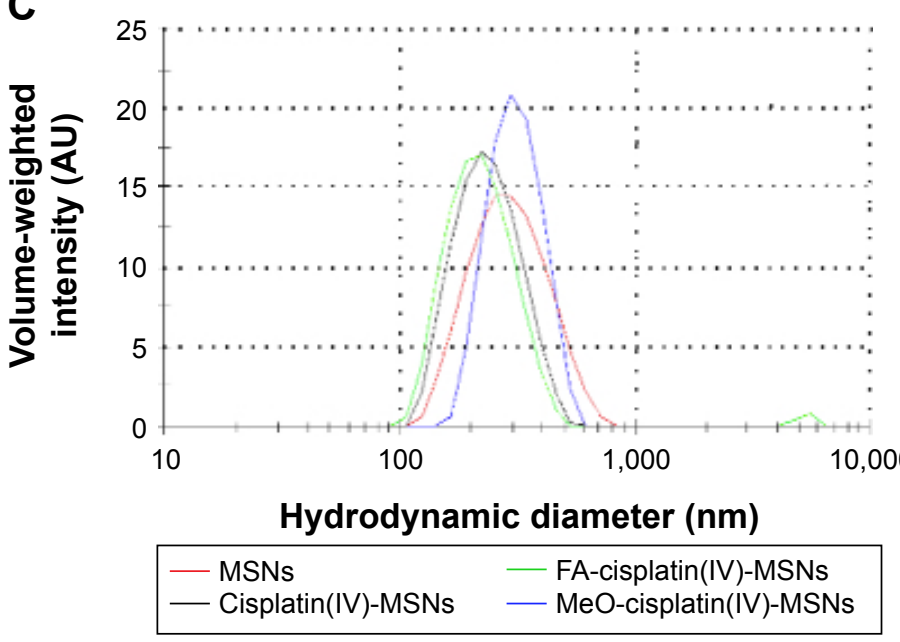

charged carboxylate groups from the cisplatin prodrug. These results confirm the successful conjugation of the cisplatin(IV) prodrug to the MSN particles. The amount of cisplatin(IV) prodrug attached to MSNs was $0.178 \mu \mathrm{mol}$ per mg of MSNs, as determined by atomic absorption spectroscopy.

To render biocompatibility and targeting abilities to the cisplatin(IV)-MSN system, an FA-PEG-silane derivative was grafted onto the surface of the cisplatin(IV)-MSNs. As expected, FA-cisplatin(IV)-MSNs showed an increase in the organic content ( $7 \mathrm{wt} \%$ ) compared with cisplatin(IV)-MSNs, due to the presence of FA-PEG chains. Because of the carboxylate group present in the FA molecule, the $\zeta$-potential of FA-cisplatin(IV)-MSNs $(-11 \mathrm{mV})$ further decreased compared to cisplatin(IV)-MSNs $(-1 \mathrm{mV})$. The hydrodynamic diameter of the targeted nanoparticles was not significantly affected by the addition of the targeting molecule $(216.1 \mathrm{~nm})$. A dramatic decrease in the surface area from 523.4 to $367 \mathrm{~m}^{2} / \mathrm{g}$ was also observed after functionalization of cisplatin(IV)-MSNs with FA-PEG-silane. The changes

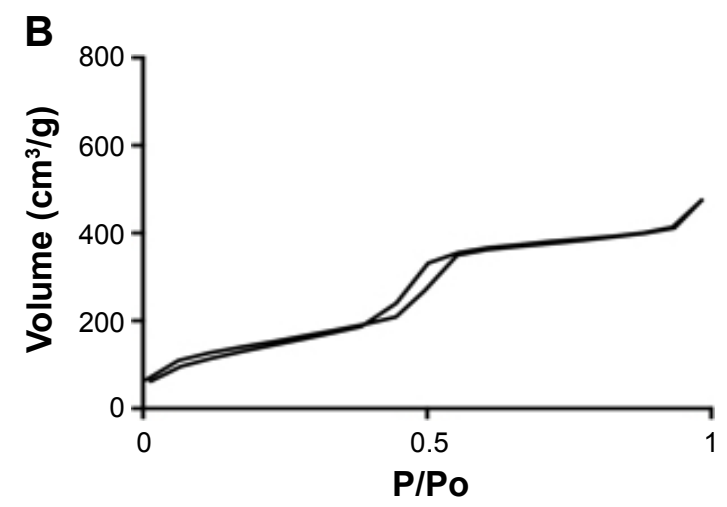

D

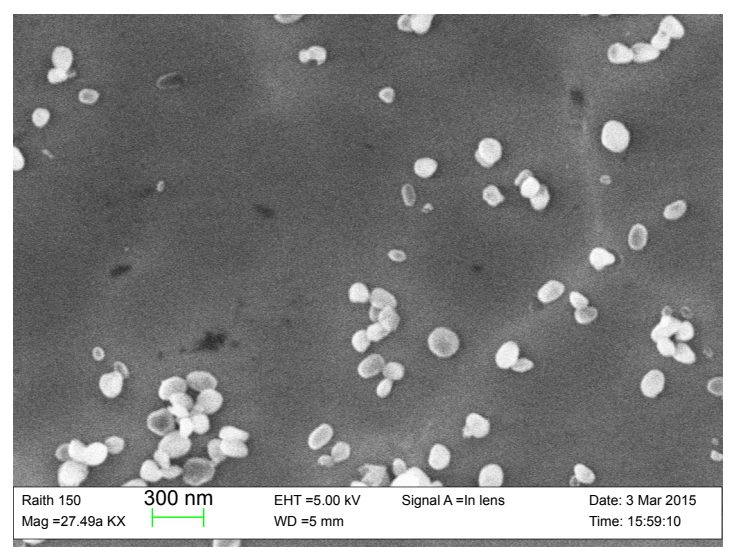

Figure 2 Structural properties of MSN materials.

Notes: (A) Nitrogen sorption isotherm of AP-MSNs; (B) nitrogen sorption isotherm of cisplatin(IV)-MSNs; (C) volume-weighted hydrodynamic diameter distributions of MSN material; (D) SEM image of AP-MSNs.

Abbreviations: AP, aminopropyl; MSNs, mesoporous silica nanoparticles; SEM, scanning electron microscopy; FA, folic acid; MeO, methoxy. 
Table I Structural properties of MSN materials synthesized in this work

\begin{tabular}{llllll}
\hline Material & $\begin{array}{l}\text { Hydrodynamic } \\
\text { diameter }(\mathbf{n m})\end{array}$ & PDI & $\begin{array}{l}\text {-potential } \\
\mathbf{( m V})\end{array}$ & $\begin{array}{l}\text { Organic } \\
\text { content }(\%)\end{array}$ & $\begin{array}{l}\text { Surface area } \\
\left(\mathbf{m}^{2} / \mathbf{g}\right)\end{array}$ \\
\hline MSNs & 272.6 & 0.094 & +34.4 & 13.9 & 766.1 \\
Cisplatin(IV)-MSNs & 222.2 & 0.088 & -1.0 & 17.1 & 523.4 \\
FA-cisplatin(IV)-MSNs & 216.1 & 0.167 & -11.0 & 24.1 & 367.0 \\
MeO-cisplatin(IV)-MSNs & 274.3 & 0.310 & -2.6 & 33.3 & 390.8 \\
\hline
\end{tabular}

Abbreviations: MSN, mesoporous silica nanoparticle; PDI, polydispersity index; FA, folic acid; MeO, methoxy.

to the structural properties of FA-cisplatin(IV)-MSNs, compared with cisplatin(IV)-MSNs, suggest that MSNs were successfully decorated with FA-PEG-silane molecules. A control MSN sample, MeO-cisplatin(IV)-MSN, which lacked only the targeting agent FA, was also synthesized and characterized (Table 1). The structural properties of MeOcisplatin(IV)-MSNs were similar to those obtained for the FA-cisplatin(IV)-MSNs with the exception of the $\zeta$-potential, which was still more neutral $(-2.6 \mathrm{mV})$, due to the absence of the additional carboxylate groups from FA.

\section{Reduction of cisplatin(IV) prodrug to cisplatin(II)}

To induce an antineoplastic effect, cisplatin must be released from the FA-cisplatin(IV)-MSNs upon reduction. Glutathione and ascorbic acid are reducing agents present in the intracellular environment of cancer cells that have the ability to reduce cisplatin(IV) complexes to cisplatin. ${ }^{12,31}$ Because this anticancer drug binds covalently to guanosine to form the cationic adduct $c i s-\mathrm{Pt}\left[\left(\mathrm{NH}_{3}\right)_{2} \mathrm{Cl}(\text { guanosine })\right]^{+}$, ESI massspectrometry studies can be used to confirm the reduction of cisplatin(IV) prodrug-delivery systems and the release of the active drug cisplatin. ${ }^{50} \mathrm{FA}$-cisplatin(IV)-MSNs were incubated with an aqueous solution containing ascorbic acid
$(17 \mathrm{mM})$ and guanosine $(0.62 \mathrm{mM})$ for 24 hours at $37^{\circ} \mathrm{C}$ The ESI mass spectrum revealed the presence of a characteristic peak for the cationic guanosine adduct $(\mathrm{m} / \mathrm{z}=547.1$, Figure 3A), indicating the successful release of cisplatin from this system under reductive conditions. On the contrary, in the absence of ascorbic acid, the guanosine-cisplatin complex was not observed (Figure 3B). These results suggest that upon cellular internalization, this redox-responsive system will be reduced to cisplatin by the reductive environment found in the cytosol of cancer cells.

\section{Internalization and localization of FA-MSNs}

Because the cytosol of cancer cells provides a highly reductive environment, the internalization of nanocarriers containing Pt(IV) prodrugs is of vital importance to release the active drug cisplatin. ${ }^{12,31,50}$ To evaluate the targeting abilities of the FA-conjugated-MSN platform developed in this work, internalization and localization studies were carried out using FITC-labeled MSNs. HeLa cells, which overexpress the folate receptor, were used for both studies. ${ }^{41,43-45}$ After exposing the cells to FA-FITC-MSNs or MeO-FITC-MSNs for 6 hours, the MFI produced by internalized nanoparticles and confocal images was obtained by flow cytometry and
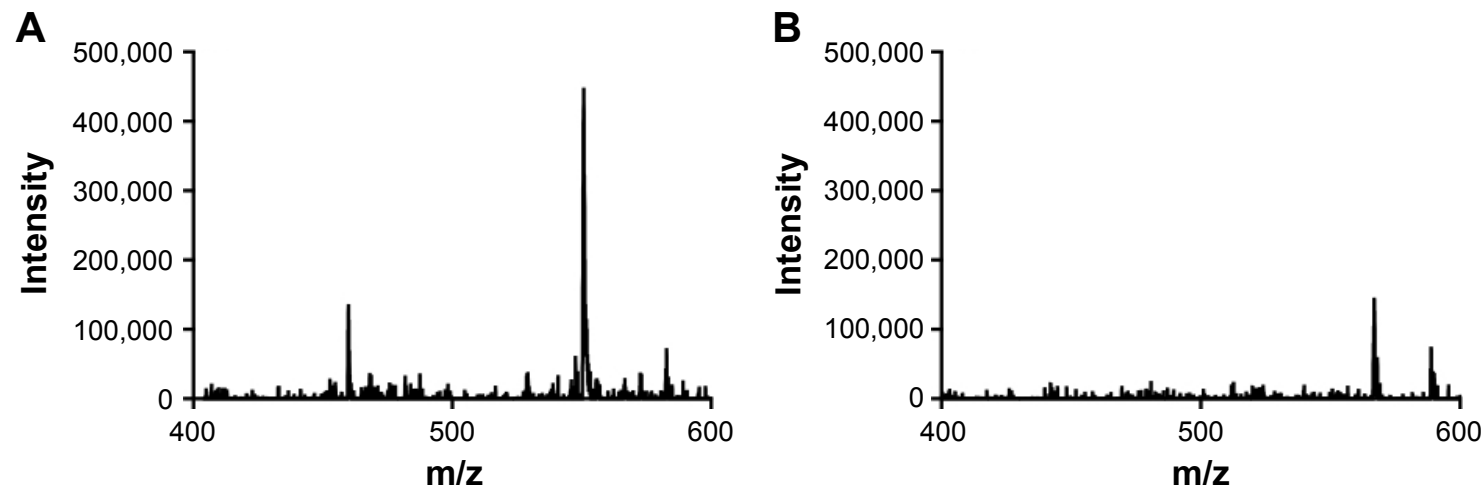

Figure 3 ESI mass spectra for the reduction of FA-cisplatin(IV)-MSNs to cisplatin.

Notes: FA-cisplatin(IV)-MSNs were incubated in the presence $(\mathbf{A})$ or absence $(\mathbf{B})$ of ascorbic acid in an aqueous solution containing guanosine for 24 hours at $37^{\circ} \mathrm{C}$. Then, the formation of the cis- $\mathrm{Pt}\left[\left(\mathrm{NH}_{3}\right)_{2} \mathrm{Cl} \text { (guanosine) }\right]^{+}$cation $(\mathrm{m} / \mathrm{z}=547.1)$ was determined by ESI mass spectrometry.

Abbreviations: ESI, electrospray ionization; FA, folic acid; MSNs, mesoporous silica nanoparticles. 


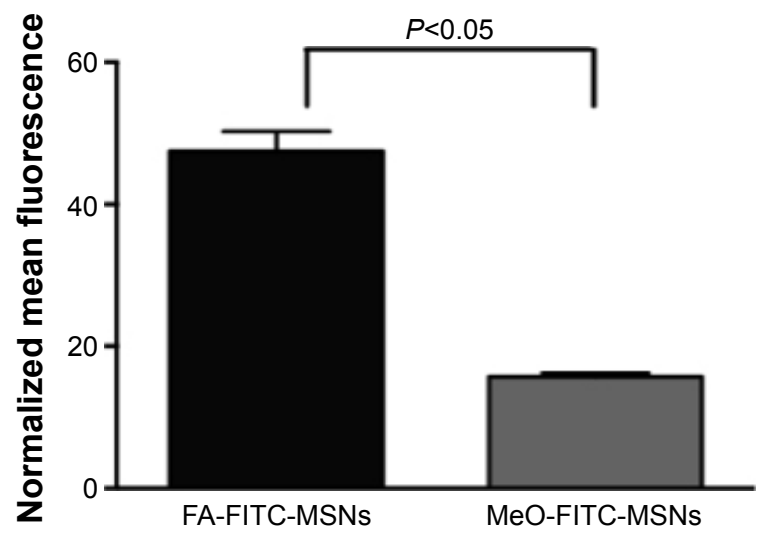

Figure 4 Internalization results by flow cytometry.

Notes: HeLa cancer cells were exposed to $100 \mu \mathrm{g} / \mathrm{mL}$ of FA-FITC-MSNs or MeOFITC-MSNs for 6 hours. Then, normalized mean fluorescence was obtained. Error bars represent the standard deviation of three independent experiments. Abbreviations: FA, folic acid; FITC, fluorescein isothiocyanate; MSNs, mesoporous silica nanoparticles; $\mathrm{MeO}$, methoxy.

confocal microscopy, respectively. As expected, the results from flow cytometry indicated that HeLa cells engulfed FA-FITC-MSNs to a higher extent than MeO-FITC-MSNs $(P<0.05)$ (Figure 4). Furthermore, confocal images confirmed that a significant number of FA-FITC-MSNs were present in the cytosol (Figure 5A-D); meanwhile, some of the MeO-FITC-MSNs were attached to the cellular membrane, but only a very small number of these nanoparticles were localized in the cytosol (Figure 5E-H). Moreover, to prove the role of folate receptors in the uptake of FA-FITC-MSN material, we performed a control experiment using different concentrations of free FA molecules to block the folate receptors present on the surface of HeLa cells (Figure S2).
The results clearly showed that the FA-decorated MSNs were internalized by the folate receptor-mediated endocytosis pathway. These results confirm that FA can be successfully used as a targeting molecule to enhance the intracellular accumulation of FA-FITC-MSN material in those cells overexpressing the folate receptor. ${ }^{43-46}$

\section{Endolysosomal escape of FA-FITC-MSNs}

Nanovehicles that are functionalized with FA enter the cell mainly by a folate receptor-mediated endocytosis mechanism. ${ }^{41}$ After internalization, these delivery vehicles are usually trafficked through the endolysosomal pathway, where they often get trapped in the endolysosomal compartments and are prevented from delivering the cargo into the cytosol. ${ }^{54}$ The escape of FA-cisplatin(IV)-MSNs from endolysosomal compartments is crucial for the reduction of the prodrug and release of cisplatin into the cytoplasm.

To determine whether internalized FA-targeted MSNs had the ability to escape from endolysosomal vesicles, microscopic studies were performed using FITC-tagged MSNs (Figure 6). Cells were incubated with FA-FITC-MSNs for different periods: 30 minutes (Figure 6A-D), 1 hour (Figure 6E-H), or 3 hours (Figure 6I-L). The colocalization of LysoTracker-Red with the green fluorescence exhibited by FA-FITC-MSNs, which resulted in yellow fluorescence, was studied as an indicator of FA-FITC-MSN entrapment into the lysosomal compartments. ${ }^{39,47}$ The results indicated that the escape of FA-FITC-MSN particles from lysosomal compartments was time-dependent. After 30 minutes of incubation, FA-FITC-MSNs were mainly localized inside
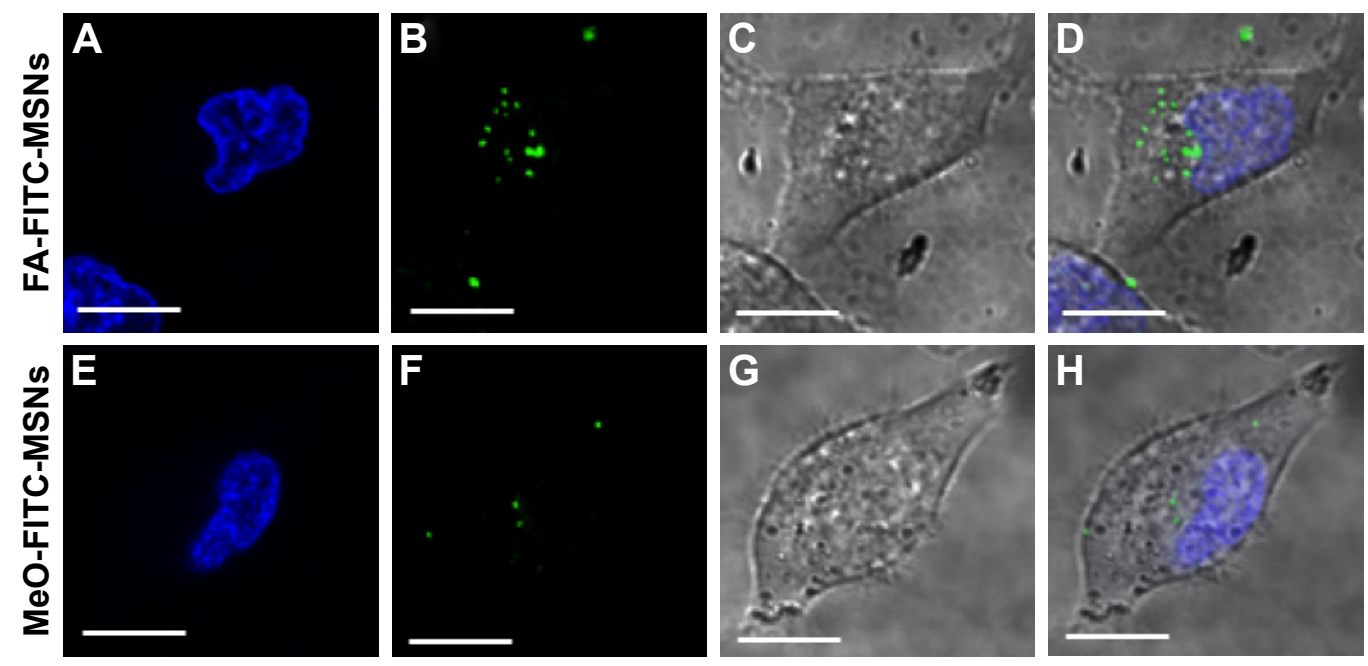

Figure 5 Localization of FA-FITC-MSNs or MeO-FITC-MSNs in HeLa cancer cells.

Notes: Cells were exposed to $100 \mu \mathrm{g} / \mathrm{mL}$ of MSN materials for 6 hours. (A, E) Nucleus (blue); (B, F) FITC-MSNs (green); (C, G) DIC; (D, H) merged. Scale bars represent $5 \mu \mathrm{m}$.

Abbreviations: FA, folic acid; FITC, fluorescein isothiocyanate; MSNs, mesoporous silica nanoparticles; MeO, methoxy; DIC, differential interference contrast. 

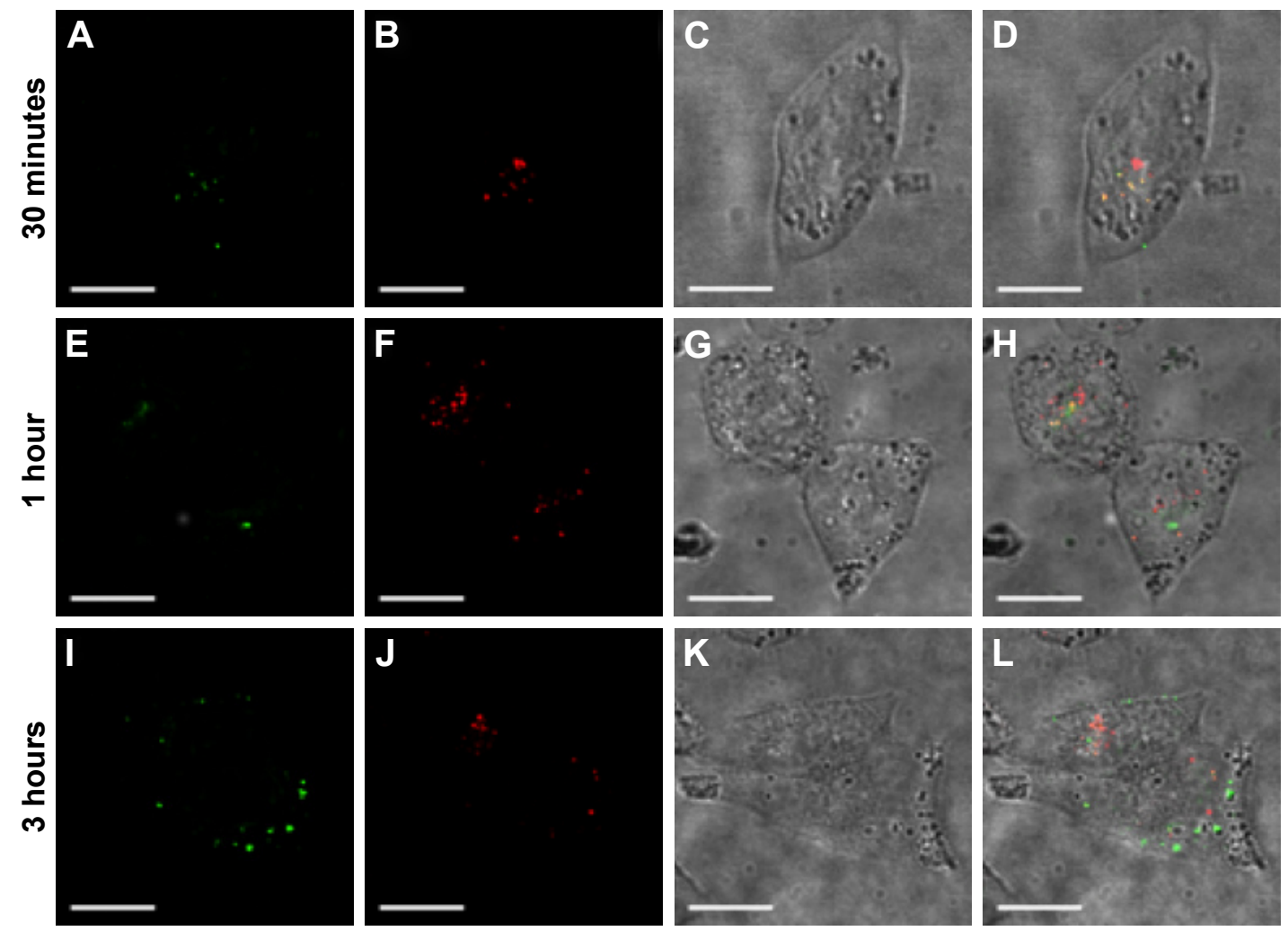

Figure 6 Escape of FA-FITC-MSNs from endolysosome compartments.

Notes: HeLa cells were treated with $100 \mu \mathrm{g} / \mathrm{mL}$ of FA-FITC-MSNs for 30 minutes, I hour, or 3 hours. (A, E, I) Nanoparticles (green); (B, F, J) endolysosome compartments (red); (C, G, K) DIC; (D, H, L) merged, overlapping of red and green (yellow). Scale bars represent $5 \mu \mathrm{m}$.

Abbreviations: FA, folic acid; FITC, fluorescein isothiocyanate; MSNs, mesoporous silica nanoparticles; DIC, differential interference contrast.

the lysosomal compartments, as demonstrated by the appearance of yellow fluorescence (Figure 6A-D). However, after 1 hour of incubation, the presence of green fluorescence in the cytosol of HeLa cells was evident, indicating that some of the FA-FITC-MSNs were able to escape from lysosomes (Figure 6E-H). Finally, after 3 hours of incubation, a significant increase in green fluorescence in the cytosol of HeLa cells was observed, indicating that most of the endocytosed FA-FITC-MSNs escaped from lysosomes (Figure 6I-L). Nevertheless, some of the MSN particles were still trapped in the lysosomal compartments, as indicated by some yellow spots in the confocal images.

These results led us to conclude that after internalization, FA-conjugated-MSNs are able to escape from those compartments and successfully deliver the cisplatin drug upon reduction in the cytosolic environment. The released cisplatin could be capable of traveling to the cell nucleus and forming DNA adducts. The mechanism by which FA-FITC-MSN material escapes from lysosomal compartments was not studied in this work; however, it has been reported that MSNs functionalized with amine groups can escape from endolysosomal compartments following the proton-sponge effect. ${ }^{47,54}$

\section{Cisplatin-DNA adducts}

Cisplatin exerts its antitumor activity by forming DNA adducts, especially the 1,2-guanine-guanine intrastrand cross-link (1,2-d[GpG]), which activates different signaltransduction pathways that lead to cell death. ${ }^{52}$ To evaluate the efficacy of cisplatin released from FA-cisplatin(IV)MSNs, the detection of 1,2-d(GpG) intrastrand adducts was evaluated. These results were compared to DNA adducts induced by free cisplatin(IV) prodrug, $\mathrm{MeO}$-cisplatin(IV)MSNs, and free cisplatin. To obtain a valid comparison, platinum concentration was used instead of cisplatin or cisplatin(IV) prodrug concentration. Cells were exposed to $6.5 \mu \mathrm{M}$ of platinum for 24 hours, and anti-intrastrand adduct fluorescence was determined by flow cytometry. DNA-adduct formation is related to an increase in antiintrastrand adduct fluorescence compared to untreated cells. ${ }^{8}$ Cells treated with free cisplatin(IV) prodrug did not show formation of DNA adducts, as shown in Figure 7. No statistically significant difference between untreated HeLa cells and cisplatin(IV) prodrug treated HeLa cells was observed. This may be attributed to the fact that the diffusion of Pt(IV) prodrugs through the cellular membrane is limited, due to 


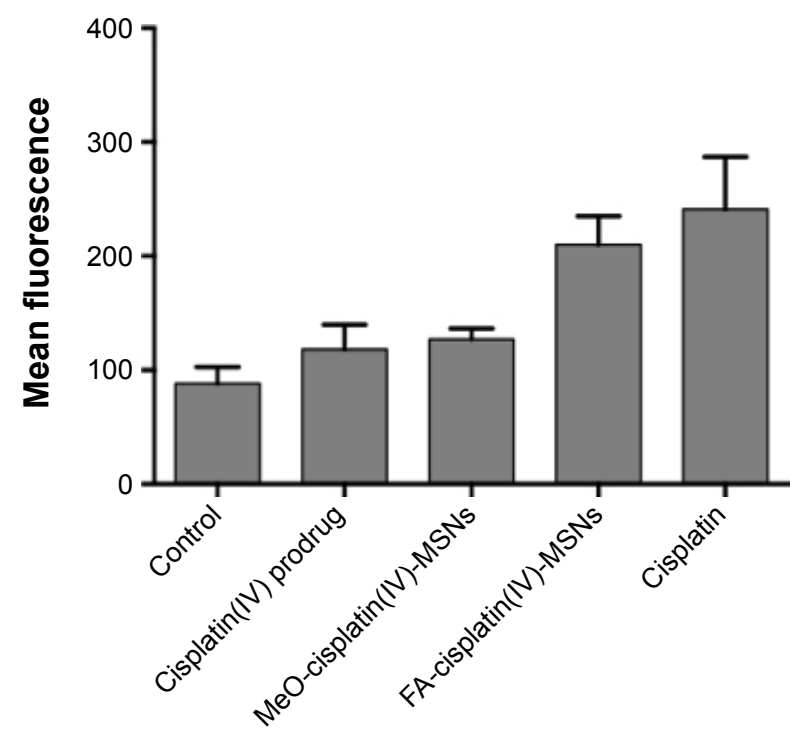

Figure 7 Cisplatin-adduct measurement by flow cytometry.

Notes: HeLa cells were exposed to $6.5 \mu \mathrm{M}$ of platinum for 24 hours, fixed in ethanol, incubated with an anticisplatin-modified DNA antibody and labeled with an antirat FITC-labeled antibody. Error bars represent the standard deviation of five independent experiments.

Abbreviations: FITC, fluorescein isothiocyanate; MeO, methoxy; MSNs, mesoporous silica nanoparticles; FA, folic acid.

the axial ligands present in Pt(IV) complexes., ${ }^{4,31}$ Samples exposed to MeO-cisplatin(IV)-MSNs had a slight increase in anti-intrastrand adduct fluorescence compared to untreated cells $(P<0.05)$. These data are in agreement with internalization studies, which indicated that only a small number of MeO-FITC-MSNs were taken up and present in the cytosol of HeLa cells (Figures 4 and 5).

These results suggest that the quantity of $\mathrm{MeO}-$ cisplatin(IV)-MSNs endocytosed was not enough to deliver a sufficient dose of cisplatin capable of inducing significant DNA adducts. Interestingly, when cells were treated with FA-cisplatin(IV)-MSNs, the cisplatin released from this system was capable of intercalating in the DNA, forming adducts (Figure 7). No statistically significant difference between cisplatin-treated cells and FA-cisplatin(IV)-MSNtreated cells was observed $(P>0.05)$, which indicates that the efficacy of the platform developed in this work is comparable with that obtained using the free drug. These results confirm that the FA-cisplatin(IV)-MSN carrier can successfully transport and release cisplatin in the cytosol of HeLa cells with therapeutically adequate amounts to afford the formation of DNA adducts.

\section{Cell viability}

Cytotoxicity studies in HeLa cells were carried out to further validate the anticancer activity of cisplatin released from FA-cisplatin(IV)-MSNs. For this experiment, platinum

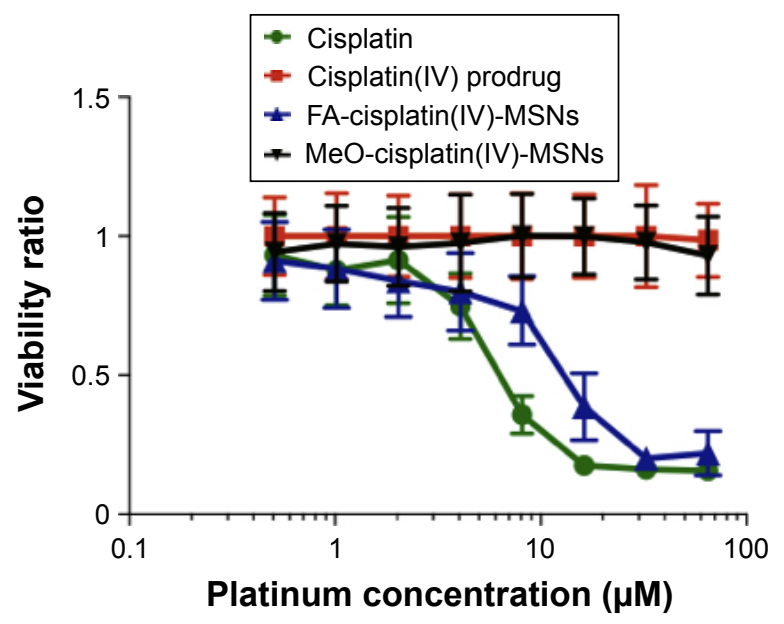

Figure 8 Dose-response curve.

Notes: HeLa cells were exposed to varying concentrations of platinum for 48 hours. Error bars represent the standard deviation of five independent experiments. Abbreviations: FA, folic acid; MSNs, mesoporous silica nanoparticles; $\mathrm{MeO}$, methoxy.

concentrations were used to allow a sound comparison between the experimental group and the controls. HeLa cells were exposed to varying concentrations of platinum for 48 hours. Afterward, samples were incubated for an additional 24 hours, after which the CellTiter assay was used to evaluate the viability ratio. HeLa cells treated with cisplatin(IV) prodrug and MeO-cisplatin(IV)-MSNs did not show a decrease in cell viability in any of the cisplatin ranges assessed. These results are consistent with the internalization and DNA adduct-formation results, which indicated that the amount of cisplatin(IV) prodrug or MeO-cisplatin(IV)-MSNs engulfed by HeLa cells was not sufficient to deliver lethal doses of cisplatin (Figures 7 and 8). However, cell death was evident when samples were exposed to FA-cisplatin(IV)MSNs (Figure 8), which agrees with observations from the internalization and DNA adduct-formation experiments. However, the efficacy of cisplatin (half-maximal inhibitory concentration $7 \mu \mathrm{M}$ ) was slightly higher than FA-cisplatin(IV)-MSNs (half-maximal inhibitory concentration $10 \mu \mathrm{M}$ ). We hypothesize that this difference in efficacy is due to the inability of some nanoparticles to escape from the endolysosome compartments, which will have an impact on the intracellular concentration of cisplatin. Overall, our results suggest that the target-specific MSN-based delivery vehicle developed in this work had the ability to target HeLa cancer cells and release a dose of cisplatin that was capable of inducing cell death almost as effectively as free cisplatin.

\section{Conclusion}

Our work demonstrated that FA-cisplatin(IV)-MSNs were able to complete the pathway of targeted delivery of cisplatin with a toxic effect comparable to that exhibited by free cisplatin. 
Results showed that the targeted nanovehicle was internalized by HeLa cells through the folate receptor-mediated endocytosis pathway and then escaped from the endolysosomal compartments into the cytosol. Cisplatin released upon reduction in the cytosol was able to reach the nuclear DNA, eventually forming adducts and inducing cell death. Although the efficacy of this drug-delivery system was not higher than that of free cisplatin, the side effects are likely to be significantly decreased using FA-cisplatin(IV)-MSNs. We believe that inducing endolysosomal membrane permeabilization could enhance the effectiveness of this nanocarrier. This will allow the release of internalized nanoparticles into the cytosol, which would increase the intracellular concentration of cisplatin. Future studies will be focused on exploring combinations of FAcisplatin(IV)-MSNs with drugs or with other treatments that could disrupt the membrane of the endolysosomal vesicles.

\section{Acknowledgments}

We thank the following funding sources for their support: UNC Charlotte (start-up funding), the Nanoscale Science Program at UNC Charlotte, NIH AREA grant 1R15CA192160-01, and NSF instrument grant 1337873. We also acknowledge Mr Jimmy Pan for helping with the synthesis and characterization of the PEG ligands and the AAS measurements. The authors are grateful to Dr Richard Jew for critical reading of the manuscript and helpful suggestions.

\section{Author contributions}

MPAB performed the synthesis and characterization of the MSN materials and the in vitro experiments. MPAB and JLVE conceived and designed the experiments and wrote the paper. All authors contributed toward data analysis, drafting and revising the paper and agree to be accountable for all aspects of the work.

\section{Disclosure}

The authors report no conflicts of interest in this work.

\section{References}

1. Chabner BA, Roberts TG Jr. Timeline: chemotherapy and the war on cancer. Nat Rev Cancer. 2005;5(1):65-72.

2. Weisse AB. From trench warfare to war on cancer: the development of chemotherapy for malignant disease. Hosp Pract (Off Ed). 1992;27(3A):141-143, 147-148.

3. Dasari S, Tchounwou PB. Cisplatin in cancer therapy: molecular mechanisms of action. Eur J Pharmacol. 2014;740:364-378.

4. Johnstone TC, Suntharalingam K, Lippard SJ. The next generation of platinum drugs: targeted $\mathrm{Pt}(\mathrm{II})$ agents, nanoparticle delivery, and $\mathrm{Pt}(\mathrm{IV})$ prodrugs. Chem Rev. 2016;116(5):3436-3486.

5. Bose RN. Biomolecular targets for platinum antitumor drugs. Mini Rev Med Chem. 2002;2(2):103-111.

6. Cvitkovic E. Cumulative toxicities from cisplatin therapy and current cytoprotective measures. Cancer Treat Rev. 1998;24(4):265-281.
7. Dhar S, Kolishetti N, Lippard SJ, Farokhzad OC. Targeted delivery of a cisplatin prodrug for safer and more effective prostate cancer therapy in vivo. Proc Natl Acad Sci U S A. 2011;108(5):1850-1855.

8. Dhar S, Gu FX, Langer R, Farokhzad OC, Lippard SJ. Targeted delivery of cisplatin to prostate cancer cells by aptamer functionalized Pt(IV) prodrug-PLGA-PEG nanoparticles. Proc Natl Acad Sci U S A. 2008; 105(45):17356-17361.

9. Hall MD, Mellor HR, Callaghan R, Hambley TW. Basis for design and development of platinum(IV) anticancer complexes. J Med Chem. 2007;50(15):3403-3411.

10. Giaccone G. Clinical perspectives on platinum resistance. Drugs. 2000;59 Suppl 4:9-17; discussion 37-38.

11. Brandon RJ, Dabrowiak JC. Synthesis, characterization, and properties of a group of platinum (IV) complexes. J Med Chem. 1984;27(7): 861-865.

12. Shi Y, Liu SA, Kerwood DJ, Goodisman J, Dabrowiak JC. Pt(IV) complexes as prodrugs for cisplatin. J Inorg Biochem. 2012;107(1):6-14.

13. Liu D, He C, Wang AZ, Lin W. Application of liposomal technologies for delivery of platinum analogs in oncology. Int J Nanomedicine. 2012; 8:3309-3319.

14. He C, Lu J, Lin W. Hybrid nanoparticles for combination therapy of cancer. J Control Release. 2015;219:224-236.

15. He C, Lu K, Liu D, Lin W. Nanoscale metal-organic frameworks for the co-delivery of cisplatin and pooled siRNAs to enhance therapeutic efficacy in drug-resistant ovarian cancer cells. J Am Chem Soc. 2014;136(14): 5181-5184.

16. Della Rocca J, Lin W. Nanoscale metal-organic frameworks: magnetic resonance imaging contrast agents and beyond. Eur J Inorg Chem. 2010;(24):3725-3734.

17. Taylor-Pashow KML, Della Rocca J, Xie Z, Tran S, Lin W. Postsynthetic modifications of iron-carboxylate nanoscale metal-organic frameworks for imaging and drug delivery. J Am Chem Soc. 2009;131(40): 14261-14263.

18. Dhar S, Daniel WL, Giljohann DA, Mirkin CA, Lippard SJ. Polyvalent oligonucleotide gold nanoparticle conjugates as delivery vehicles for platinum(IV) warheads. J Am Chem Soc. 2009;131(41):14652-14653.

19. Shi Y, Goodisman J, Dabrowiak JC. Cyclodextrin capped gold nanoparticles as a delivery vehicle for a prodrug of cisplatin. Inorg Chem. 2013; 52(16):9418-9426.

20. Ma PA, Xiao HH, Li CX, et al. Inorganic nanocarriers for platinum drug delivery. Mater Today (Kidlington). 2015;18(10):554-564.

21. Rocca JD, Werner ME, Kramer SA, et al. Polysilsesquioxane nanoparticles for triggered release of cisplatin and effective cancer chemoradiotherapy. Nanomedicine. 2015;11(1):31-38.

22. Della Rocca J, Huxford RC, Comstock-Duggan E, Lin W. Polysilsesquioxane nanoparticles for targeted platin-based cancer chemotherapy by triggered release. Angew Chem Int Ed Engl. 2011;50(44):10330-10334.

23. Angelos S, Johansson E, Stoddart JF, Zink JI. Mesostructured silica supports for functional materials and molecular machines. Adv Funct Mater. 2007;17(14):2261-2271.

24. Slowing II, Vivero-Escoto JL, Wu CW, Lin VS. Mesoporous silica nanoparticles as controlled release drug delivery and gene transfection carriers. Adv Drug Deliv Rev. 2008;60(11):1278-1288.

25. Vivero-Escoto JL, Huang YT. Inorganic-organic hybrid nanomaterials for therapeutic and diagnostic imaging applications. Int J Mol Sci. 2011;12(6):3888-3927.

26. Vivero-Escoto JL, Slowing II, Trewyn BG, Lin VS. Mesoporous silica nanoparticles for intracellular controlled drug delivery. Small. 2010;6(18):1952-1967.

27. Wu KC, Yamauchi Y. Controlling physical features of mesoporous silica nanoparticles (MSNs) for emerging applications. J Mater Chem. 2012; 22(4):1251-1256.

28. Gu J, Su S, Li Y, He Q, Zhong J, Shi J. Surface modification-complexation strategy for cisplatin loading in mesoporous nanoparticles. J Phys Chem Lett. 2010;1(24):3446-3450.

29. Gu J, Liu J, Li Y, Zhao W, Shi J. One-pot synthesis of mesoporous silica nanocarriers with tunable particle sizes and pendent carboxylic groups for cisplatin delivery. Langmuir. 2013;29(1):403-410. 
30. Zhu X, Gu J, Li Y, Zhao W, Shi J. Magnetic core-mesoporous shell nanocarriers with drug anchorages suspended in mesopore interior for cisplatin delivery. Microporous Mesoporous Mater. 2014;196: 115-121.

31. Ahn B, Park J, Singha K, Park H, Kim WJ. Mesoporous silica nanoparticle-based cisplatin prodrug delivery and anticancer effect under reductive cellular environment. JMater Chem B Mater Biol Med. 2013;1(22):2829-2836.

32. Mohapatra S, Rout SR, Narayan R, Maiti TK. Multifunctional mesoporous hollow silica nanocapsules for targeted co-delivery of cisplatin-pemetrexed and MR imaging. Dalton Trans. 2014;43(42):15841-15850.

33. Munaweera I, Shi Y, Koneru B, et al. Nitric oxide- and cisplatinreleasing silica nanoparticles for use against non-small cell lung cancer. J Inorg Biochem. 2015;153:23-31.

34. Vivero-Escoto JL, Elnagheeb M. Mesoporous silica nanoparticles loaded with cisplatin and phthalocyanine for combination chemotherapy and photodynamic therapy in vitro. Nanomaterials. 2015;5(4): 2302-2316.

35. Zhang W, Shen J, Su H, et al. Co-delivery of cisplatin prodrug and chlorin 66 by mesoporous silica nanoparticles for chemo-photodynamic combination therapy to combat drug resistance. ACS Appl Mater Interfaces. 2016;8(21):13332-13340.

36. Master AM, Gupta AS. EGF receptor-targeted nanocarriers for enhanced cancer treatment. Nanomedicine (Lond). 2012;7(12):1895-1906.

37. Shi M, Lu J, Shoichet MS. Organic nanoscale drug carriers coupled with ligands for targeted drug delivery in cancer. JMater Chem. 2009;19(31): 5485-5498.

38. Yu BO, Tai HC, Xue W, Lee LJ, Lee RJ. Receptor-targeted nanocarriers for therapeutic delivery to cancer. Mol Membr Biol. 2010;27(7): 286-298.

39. Walker WA, Tarannum M, Vivero-Escoto JL. Cellular endocytosis and trafficking of cholera toxin B-modified mesoporous silica nanoparticles. J Mater Chem B Mater Biol Med. 2016;4(7):1254-1262.

40. Yang SJ, Lin FH, Tsai KC, et al. Folic acid-conjugated chitosan nanoparticles enhanced protoporphyrin IX accumulation in colorectal cancer cells. Bioconjug Chem. 2010;21(4):679-689.

41. Zwicke GL, Mansoori GA, Jeffery CJ. Utilizing the folate receptor for active targeting of cancer nanotherapeutics. Nano Rev. 2012;3: 18496

42. Ferreira TH, Marino A, Rocca A, et al. Folate-grafted boron nitride nanotubes: possible exploitation in cancer therapy. Int J Pharm. 2015; 481(1-2):56-63.
43. Liu Y, Mi Y, Zhao J, Feng SS. Multifunctional silica nanoparticles for targeted delivery of hydrophobic imaging and therapeutic agents. Int J Pharm. 2011;421(2):370-378.

44. Ma X, Zhao Y, Ng KW, Zhao Y. Integrated hollow mesoporous silica nanoparticles for target drug/siRNA co-delivery. Chemistry. 2013; 19(46):15593-15603.

45. Wu H, Liu G, Zhang S, et al. Biocompatibility, MR imaging and targeted drug delivery of a rattle-type magnetic mesoporous silica nanosphere system conjugated with PEG and cancer-cell-specific ligands. J Mater Chem. 2011;21(9):3037-3045.

46. Xiong L, Du X, Kleitz F, Qiao SZ. Cancer-cell-specific nuclear-targeted drug delivery by dual-ligand-modified mesoporous silica nanoparticles. Small. 2015;11(44):5919-5926.

47. Slowing I, Trewyn BG, Lin VS. Effect of surface functionalization of MCM-41-type mesoporous silica nanoparticles on the endocytosis by human cancer cells. J Am Chem Soc. 2006;128(46):14792-14793.

48. Kikkeri R, Lepenies B, Adibekian A, Laurino P, Seeberger PH. In vitro imaging and in vivo liver targeting with carbohydrate capped quantum dots. J Am Chem Soc. 2009;131(6):2110-2112.

49. Patil YB, Toti US, Khdair A, Ma L, Panyam J. Single-step surface functionalization of polymeric nanoparticles for targeted drug delivery. Biomaterials. 2009;30(5):859-866.

50. Zheng YR, Suntharalingam K, Johnstone TC, Lippard SJ. Encapsulation of $\mathrm{Pt}(\mathrm{IV})$ prodrugs within a $\mathrm{Pt}(\mathrm{II})$ cage for drug delivery. Chem Sci. 2015;6(2):1189-1193.

51. Barr MP, Gray SG, Hoffmann AC, et al. Generation and characterisation of cisplatin-resistant non-small cell lung cancer cell lines displaying a stem-like signature. PLoS One. 2013;8(1):e54193.

52. Liedert B, Pluim D, Schellens J, Thomale J. Adduct-specific monoclonal antibodies for the measurement of cisplatin-induced DNA lesions in individual cell nuclei. Nucleic Acids Res. 2006;34(6):e47.

53. Lundholm L, Hååg $\mathrm{P}$, Zong $\mathrm{D}$, et al. Resistance to DNA-damaging treatment in non-small cell lung cancer tumor-initiating cells involves reduced DNA-PK/ATM activation and diminished cell cycle arrest. Cell Death Dis. 2013;4:e478.

54. Panyam J, Zhou WZ, Prabha S, Sahoo SK, Labhasetwar V. Rapid endo-lysosomal escape of poly(DL-lactide-co-glycolide) nanoparticles: implications for drug and gene delivery. FASEB J. 2002;16(10): 1217-1226. 


\section{Supplementary materials Synthesis of FA-PEG ${ }_{2 K}-\mathrm{NH}_{2}$}

The synthesis of folic acid (FA)-polyethylene glycol $(\mathrm{PEG})_{2 \mathrm{~K}}-\mathrm{NH}_{2}$ was carried out through a multistep approach (Figure S1). First, diamino- $\mathrm{PEG}_{2 \mathrm{~K}}$ was synthesized and reacted with folate-NHS. To synthesize diazido- $\mathrm{PEG}_{2 \mathrm{~K}}, 2$ $\mathrm{g}$ of PEG (1 mmol) was dried under vacuum overnight. The following day, the dried PEG was combined with 1.62 $\mathrm{mL}$ of methanesulfonyl chloride $(21 \mathrm{mmol})$ in anhydrous tetrahydrofuran (THF; $10 \mathrm{~mL}$ ) at $70^{\circ} \mathrm{C}$. The mixture was then stirred in an ice bath under $\mathrm{N}_{2}$ atmosphere, followed by the addition of a solution of $3.06 \mathrm{~mL}$ of diisopropylethylamine $(17.6 \mathrm{mmol})$ in THF $(10 \mathrm{~mL})$ dropwise over 30 minutes. Thereafter, the solution was stirred for 1 hour, followed by removal of the reaction flask from the ice bath. The mixture was stirred overnight at room temperature. The newly formed solid was dissolved by the addition of cold $\mathrm{H}_{2} \mathrm{O}(10 \mathrm{~mL})$ in an ice bath. Next, $1 \mathrm{~N}$ sodium bicarbonate $(2 \mathrm{~mL})$ and $1.5 \mathrm{~g}$ sodium azide $(23.1 \mathrm{mmol})$ were added to the solution. THF was removed from the mixture using rotatory evaporation, and the aqueous phase was refluxed at $100^{\circ} \mathrm{C}$ for 24 hours with stirring. The product was obtained after extraction with dichloromethane $(5 \times 15 \mathrm{~mL})$, followed by washing steps with brine $(5 \times 15 \mathrm{~mL})$ and removal of excess water in the presence of magnesium sulfate. Dichloromethane was removed by rotary evaporation to afford the final product, diazido- $\mathrm{PEG}_{2 \mathrm{~K}}$, as a solid white compound $(2.1 \mathrm{~g}, 84 \%)$. The product was dried under high vacuum and stored at $-20^{\circ} \mathrm{C}$. The diazido- $\mathrm{PEG}_{2 \mathrm{~K}}$ polymer was confirmed by the stretching vibration of the azido group in infrared (IR; $2,110 \mathrm{~cm}^{-1}$ ). The shift of methylene protons suggested a successful synthesis of PEG- $\mathrm{N}_{3}$ from PEG. The ethylene carbons also showed a shift from the starting material - PEG. IR values were 1,102 $\mathrm{cm}^{-1}(\mathrm{C}-\mathrm{O})$ and $2,110 \mathrm{~cm}^{-1}$ (azide), and ${ }^{1} \mathrm{H}$-nuclear magnetic resonance (NMR; $300 \mathrm{MHz}, \mathrm{CDCl}_{3}$ ) values were $\delta_{\mathrm{H}}, \mathrm{ppm}(\mathrm{t}$, 4H, 3.32-3.42), (m, 168H, 3.54-3.76).

To synthesize diamino- $\mathrm{PEG}_{2 \mathrm{~K}}, 1.36 \mathrm{~g}$ of diazido- $\mathrm{PEG}_{2 \mathrm{~K}}$ $(680 \mu \mathrm{mol})$ was combined with $2.1 \mathrm{~g}$ triphenylphosphine $(8 \mathrm{mmol})$ in anhydrous THF $(10 \mathrm{~mL})$. This solution was stirred under $\mathrm{N}_{2}$ atmosphere at room temperature overnight. After that, $\mathrm{H}_{2} \mathrm{O}(510 \mu \mathrm{L})$ was added and the mixture again stirred overnight. THF was removed by rotary evaporation, and water $(17 \mathrm{~mL})$ was added. A white solid was formed (triphenylphosphine oxide) immediately after the addition of $\mathrm{H}_{2} \mathrm{O}$. The solid and $\mathrm{H}_{2} \mathrm{O}$ were removed by gravity filtration and rotary evaporation, respectively. Finally, a yellowish solid (1.3 g, 98\%) corresponding to diamino$\mathrm{PEG}_{2 \mathrm{~K}}$ was dried under high vacuum and stored at $-20^{\circ} \mathrm{C}$. The diamino- $\mathrm{PEG}_{2 \mathrm{~K}}$ product was confirmed by the disappearance of the stretching vibration for the azido group in
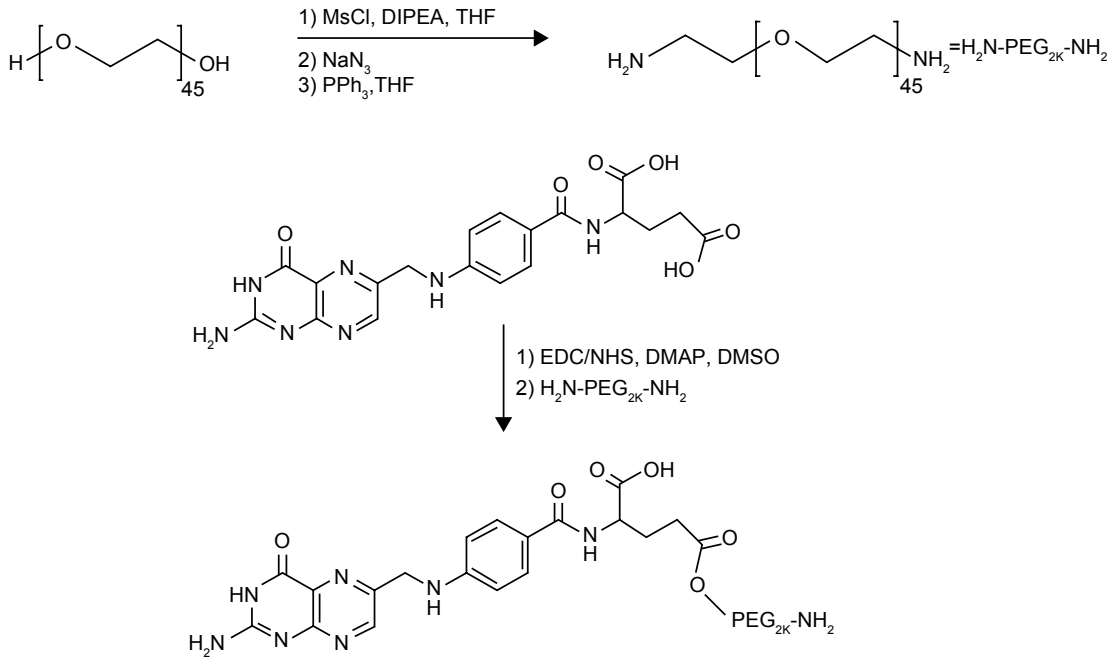

Figure SI Schematic representation of the synthesis of FA-PEG-NH

Notes: To convert the alcohol group in the $\mathrm{PEG}_{2 \mathrm{~K}}$ chain to amine group, the polymer was reacted with $\mathrm{MsCl}$ in anhydrous THF to afford a good leaving group. The PEG mesylate derivative was reacted with $\mathrm{NaN}_{3}$, a strong nucleophile, to afford the azido-PEG product. To convert the diazido-PEG ${ }_{2 K}$ derivative to the corresponding diamino$\mathrm{PEG}_{2 \mathrm{~K}}$, a mild reduction was carried out by following Staudinger reaction conditions. The diazido- $\mathrm{PEG}_{2 \mathrm{~K}}$ chain was reacted with $\mathrm{PPh} \mathrm{h}_{3}$ in anhydrous $\mathrm{THF}$ to generate the corresponding iminophosphorane. An aqueous workup led to the desired diamino-PEG ${ }_{2 K}$ derivative and the very stable phosphine oxide as by-product. The diamino-PEG polymer was further reacted with FA to afford the FA-PEG-NH targeting ligand. Firstly, the carboxylic acid group in the FA molecule was activated by using a coupling reaction in the presence of EDC and NHS. The succinimide ester derivative enhanced the reactivity of the FA toward nucleophilic substitution by amines.

Abbreviations: FA, folic acid; PEG, polyethylene glycol; THF, tetrahydrofuran; EDC, N-(3-dimethylaminopropyl)-N'-ethylcarbodiimide hydrochloride; NHS, $\mathrm{N}$-hydroxysuccinimide; DIPEA, diisopropylethylamine; DMAP, dimethylaminopyridine; DMSO, dimethyl sulfoxide. 
the IR and the chemical shift of methylene protons close to the amine groups at 2.91-2.97 ppm: IR 1,102 $\mathrm{cm}^{-1}(\mathrm{C}-\mathrm{O})$; ${ }^{1} \mathrm{H}-\mathrm{NMR}\left(300 \mathrm{MHz}\right.$; d - -methanol) $\delta_{\mathrm{H}}$, ppm (t, 4H, 2.91-2.97), (m, 168H, 3.54-3.76).

To synthesize FA-succinimide ester (SE), $1.5 \mathrm{~g}$ of FA (3.4 mmol) was combined with $978 \mathrm{mg}$ of $N$-hydroxysuccinimide (NHS; $8.5 \mathrm{mmol}), 622 \mathrm{mg}$ of 4-dimethylaminopyridine (5.1 mmol), and $1.3 \mathrm{~g}$ of $N$-(3-dimethylaminopropyl)- $N^{\prime}$ ethylcarbodiimide hydrochloride (EDC; $6.8 \mathrm{mmol})$ in anhydrous dimethyl sulfoxide (DMSO; $50 \mathrm{~mL}$ ). The solution was stirred for 48 hours at room temperature. The succinimide ester derivative was dried using a lyophilizer. The final product, a yellow solid, was stored at $-20^{\circ} \mathrm{C}$. The partial esterification of FA was confirmed by the appearance of the succinimide group in the IR. The appearance of the ethylene protons in the ${ }^{1} \mathrm{H}-\mathrm{NMR}$ provided evidence for the presence of SE. IR: $1,688 \mathrm{~cm}^{-1}$ (FA), $1,718 \mathrm{~cm}^{-1}$ (ester), $1,782 \mathrm{~cm}^{-1}$ (NHS), 1,820 cm-1 (NHS); ${ }^{1} \mathrm{H}-\mathrm{NMR}\left(300 \mathrm{MHz}, \mathrm{d}_{6}\right.$-DMSO): $\delta_{\mathrm{H}}$, ppm (m, 2H, 1.85-2.12), (t, 2H, 2.28-2.34), (s broad, $4 \mathrm{H}, 2.79)$, (m, 1H, 4.31-4.35), (d, 2H, 4.47-4.49), (d, 2H, 6.62-6.65), (t, 1H, 6.92-6.96), (d, 2H, 7.63-7.66), (d, 1H, 8.12-8.14), (s broad, 1H, 8.65).

To synthesize FA-PEG ${ }_{2 \mathrm{~K}}-\mathrm{NH}_{2}, 432 \mathrm{mg}$ of diamino- $\mathrm{PEG}_{2 \mathrm{~K}}$ (216 $\mu \mathrm{mol})$ was combined with $175 \mathrm{mg}$ FA-SE $(325 \mu \mathrm{mol})$ in DMSO $(20 \mathrm{~mL})$. The mixture was stirred for 48 hours at room temperature. The material was purified by dialysis with water for 7 days, changing the water twice per day (Slide-ALyzer $^{\mathrm{TM}}$ dialysis cassette; molecular weight cutoff 2,000). The dialyzed solution was dried using the lyophilizer. The final product, a yellow solid, was stored at $-20^{\circ} \mathrm{C}$. The product was confirmed by the appearance of an amide bond in the IR compared to the starting FA material. The target molecule was purified using dialysis, and the monosubstitution was visualized using ${ }^{1} \mathrm{H}-\mathrm{NMR}$. The integration for the polymer, PEG, and the FA protons suggested a monosubstituted product was obtained after dialysis. Yield: $105 \mathrm{mg}, 20 \%$; IR: $1,101 \mathrm{~cm}^{-1}$ (C-O), 1,644 cm-1 (amide), 1,686 cm-1 (FA); ${ }^{1} \mathrm{H}-\mathrm{NMR}\left(300 \mathrm{MHz}, \mathrm{d}_{6}\right.$-DMSO): $\delta_{\mathrm{H}}, \mathrm{ppm}(\mathrm{m}, 2 \mathrm{H}, 1.85-2.12)$, (t, 2H, 2.28-2.34), (m, 90H, 3.54-3.78), (m, 1H, 4.31-4.35), (d, 2H, 4.47-4.49), (d, 2H, 6.62-6.65), (t, 1H, 6.92-6.96), (d, $2 \mathrm{H}, 7.63-7.66),(\mathrm{d}, 1 \mathrm{H}, 8.12-8.14)$, (s broad, $1 \mathrm{H}, 8.65) ;{ }^{13} \mathrm{C}-$ NMR (500 MHz; $\left.\mathrm{D}_{2} \mathrm{O}\right): \delta_{\mathrm{C}} 28.56,32.74,34.4,39.1,45.81$, $51.99,69.36,112.55,121.9,127.58,129.1,148.81,150.82$, $156,162,169.66,175.71$.

\section{Synthesis of $\mathrm{MeO}-\mathrm{PEG}_{2 \mathrm{~K}}$-silane}

To synthesize methoxy (MeO)- $\mathrm{PEG}_{2 \mathrm{~K}}$-silane, $302.2 \mathrm{mg}$ $(0.15 \mathrm{mmol})$ of $\mathrm{MeO}-\mathrm{PEG}_{2 \mathrm{~K}}$ were dried at $90^{\circ} \mathrm{C}$ overnight. The dehydrated $\mathrm{MeO}-\mathrm{PEG}_{2 \mathrm{~K}}$ was dissolved in $10 \mathrm{~mL}$ of dichloromethane, the solution was placed in an ice bath, and $40.4 \mu \mathrm{L}$ of 3-(triethoxysilyl)propyl isocyanate was added. The solution was stirred overnight. After this period of time, the product was concentrated by rotary evaporation and dried in a vacuum. ${ }^{1} \mathrm{H}-\mathrm{NMR}(300 \mathrm{MHz}): \delta(\mathrm{t}, 2 \mathrm{H}, 0.85),(\mathrm{t}, 9 \mathrm{H}$, 1.23), (m, 2H, 1.26), (t, 2H, 2.69), (s, 3H, 3.3), (q, 6H, 3.4), (m, 164H, 3.63-3.68); ${ }^{13} \mathrm{C}-\mathrm{NMR}$ (75 MHz,): $\delta 13.1,29.76$, $53.52,59.55,68.81,70.89,157.44$.

\section{Mechanism of FA-FITC-MSN uptake}

HeLa cancer cells were incubated with media containing $100 \mathrm{mg} / \mathrm{L}$ or $500 \mathrm{mg} / \mathrm{L}$ of free folic acid for 24 hours and exposed to $50 \mu \mathrm{g} / \mathrm{mL}$ of FA-fluorescein isothiocyanate (FITC)-mesoporous silica nanoparticles (MSNs) or MeOFITC-MSNs for 4 hours. After this incubation period, cells were washed twice with warm Roswell Park Memorial Institute medium, trypsinized, resuspended in a phosphatebuffered saline solution containing $0.11 \%$ of trypan blue, and analyzed using BD LSRFortessa flow cytometry. Results are shown as normalized mean fluorescence intensity $\left(\mathrm{MFI}_{\text {treated }}-\mathrm{MFI}_{\text {control }}\right) / \mathrm{MFI}_{\text {control }} \cdot \mathrm{MFI}_{\text {treated }}$ represents the mean fluorescence intensity of samples treated with $50 \mu \mathrm{g} / \mathrm{mL}$ of nanoparticles (FA-FITC-MSNs or MeO-FITC-MSNs), and $\mathrm{MFI}_{\text {control }}$ represents the mean fluorescence intensity of untreated cells. The results showed that the internalization of FA-FITC-MSNs was inhibited by the presence of free FA molecules (Figure S2), which confirmed that FAFITC-MSNs were internalized by folate receptor-mediated endocytosis.

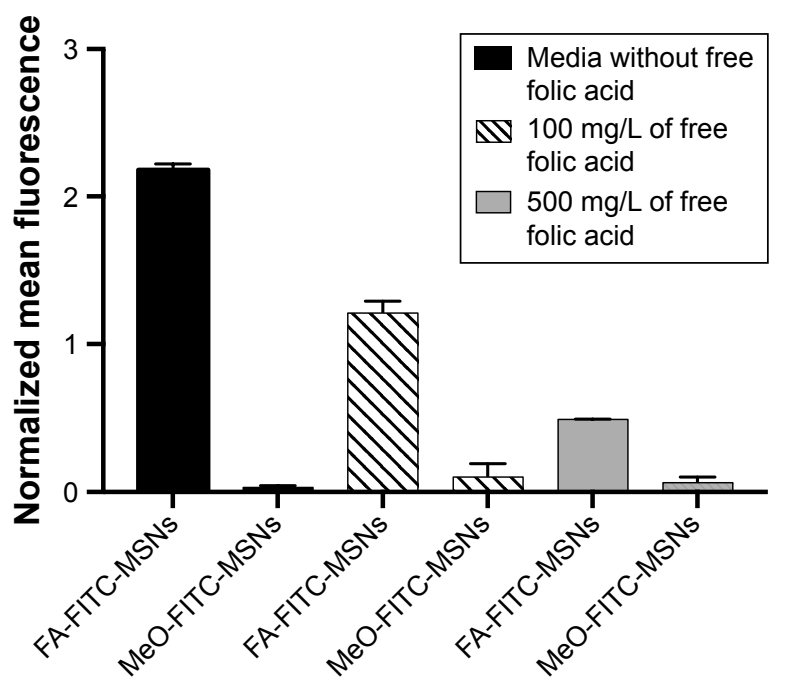

Figure S2 Internalization results by flow cytometry.

Notes: HeLa cancer cells were incubated with media containing $100 \mathrm{mg} / \mathrm{L}$ or $500 \mathrm{mg} / \mathrm{L}$ of free FA for 24 hours and exposed to $50 \mu \mathrm{g} / \mathrm{mL}$ of FA-FITC-MSNs or MeO-FITC-MSNs for 4 hours. Then, normalized mean fluorescence was obtained. Error bars represent the standard deviation of three independent experiments. Abbreviations: FA, folic acid; FITC, fluorescein isothiocyanate; MSNs, mesoporous silica nanoparticles; $\mathrm{MeO}$, methoxy. 
International Journal of Nanomedicine

Dovepress

\section{Publish your work in this journal}

The International Journal of Nanomedicine is an international, peerreviewed journal focusing on the application of nanotechnology in diagnostics, therapeutics, and drug delivery systems throughout the biomedical field. This journal is indexed on PubMed Central, MedLine, CAS, SciSearch ${ }^{\circledR}$, Current Contents ${ }^{\circledR} /$ Clinical Medicine,
Journal Citation Reports/Science Edition, EMBase, Scopus and the Elsevier Bibliographic databases. The manuscript management system is completely online and includes a very quick and fair peer-review system, which is all easy to use. Visit http://www.dovepress.com/ testimonials.php to read real quotes from published authors.

Submit your manuscript here: http://www.dovepress.com/international-journal-of-nanomedicine-journal 